\title{
Water-Soluble $\mathrm{C}_{60}$ Protects Against Bleomycin- Induced Pulmonary Fibrosis in Mice
}

This article was published in the following Dove Press journal:

International Journal of Nanomedicine

\author{
Run Dong ${ }^{1,2, *}$ \\ Min $\mathrm{Liu}^{3, *}$ \\ Xiao-Xi Huang ${ }^{4}$ \\ Zheng Liu ${ }^{4}$ \\ Ding-Yuan Jiang ${ }^{5}$ \\ Hui-Juan Xiao' \\ Jing Geng $\mathbb{D}^{5}$ \\ Yan-Hong Ren ${ }^{5}$ \\ Hua-Ping $\mathrm{Dai}^{5}$
}

'Beijing Key Laboratory of Respiratory and Pulmonary Circulation Disorders,

Department of Respiratory Medicine, Capital Medical University, Beijing,

People's Republic of China; ${ }^{2}$ Department of Respiratory Medicine, Zhengzhou

Central Hospital, Zhengzhou, People's

Republic of China; ${ }^{3}$ Department of

Radiology, China-japan Friendship

Hospital, Beijing, People's Republic of

China; ${ }^{4}$ Beijing Key Laboratory of

Respiratory and Pulmonary Circulation

Disorders, Department of Medical

Research, Beijing Chao-Yang Hospital,

Capital Medical University, Beijing,

People's Republic of China; ${ }^{5}$ Department

of Pulmonary and Critical Care Medicine,

Center of Respiratory Medicine, ChinaJapan Friendship Hospital; National

Clinical Research Center for Respiratory

Diseases; Capital Medical University,

Beijing, People's Republic of China

*These authors contributed equally to this work
Correspondence: Hua-Ping Dai

Department of Pulmonary and Critical

Care Medicine, China-Japan Friendship

Hospital, Beijing 100029, People's

Republic of China

Email daihuaping@ccmu.edu.cn
Background: Idiopathic pulmonary fibrosis (IPF) is a chronic, progressive, fibrotic interstitial pneumonia. And, oxidation/antioxidant imbalance plays an important role in the progress of IPF. Fullerene is considered to be a novel "structural" antioxidant. This study aimed to explore if water-soluble $\mathrm{C}_{60}\left(\mathrm{C}_{60}(\mathrm{OH})_{22}\right)$ can exhibit antifibrotic activity in its antioxidant role.

Methods: Healthy C57BL/6J mice were randomly grouped and induced pulmonary fibrosis by intratracheal injection of bleomycin.

Results: The survival rate of mice was observed and found that $10 \mathrm{mg} / \mathrm{kg}$ was the optimal dose of water-soluble $\mathrm{C}_{60}$ for pulmonary fibrosis. We observed that water-soluble $\mathrm{C}_{60}$ can alleviate the severity of pulmonary fibrosis by observing the chest computed tomography, pulmonary pathology, and content of collagen, alpha smooth muscle actin and fibronectin in lung. Compared with bleomycin group, ROS, the content of TNF- $\alpha$ in BALF, and the number of fibroblasts was significantly decreased and the number of type II alveolar epithelial cells was increased after treatment with C60.

Conclusion: Therefore, thanks to its powerful antioxidant action, water-soluble $\mathrm{C}_{60}$ can reduce the severity of pulmonary fibrosis induced by bleomycin in mice.

Keywords: pulmonary fibrosis, bleomycin, water-soluble $\mathrm{C}_{60}$, mice

\section{Introduction}

Idiopathic pulmonary fibrosis (IPF) is defined as a specific form of chronic, progressive fibrosing interstitial pneumonia with unknown causes. The median survival time of IPF patients is 2-3 years from diagnosis with a 5-year mortality of $30-50 \%$. There is no effect therapy except lung transplantation. ${ }^{1}$ Furthermore, potent new agents are urgently needed.

The pathogenic mechanisms of IPF remain unclear. It is currently believed that IPF originates from the abnormal repair of alveolar epithelium after repeated minor damage, which leads to scarring and lung tissue destruction. ${ }^{2}$ For the past few years, it is discovered that oxidation/antioxidant imbalance plays an important role in the progress of IPF. ${ }^{3}$ Reduced oxidative stress can reduce the degree of pulmonary fibrosis. ${ }^{4}$

Oxidative stress is an imbalance between oxidants such as reactive oxygen species (ROS) and antioxidants, which may affect lipids, DNA, carbohydrates and proteins. ROS is free radical generated physiologically during oxidative phosphorylation, including superoxide anion, hydroxyl and hydrogen peroxide. It has various physiological roles such as causing cell dysfunction and death. Research has shown that oxidants and myeloperoxidase of cells in bronchoalveolar lavage fluid (BALF) increased to a higher concentration in IPF patients, ${ }^{5}$ and the epithelial 
injury in IPF was related to the increasing activity of peroxidase. Daniil et al had determined oxidative burden in serum based on analysis of hydroperoxides ${ }^{6}$ and found that systemic oxidative stress level in IPF was significantly higher than that in control, and it was negatively correlated with dyspnea severity and lung function marked by forced vital capacity and diffuse lung capacity for carbon monoxide. In summary, the oxidation/antioxidant imbalance is related to the progression of idiopathic pulmonary fibrosis.

Fullerene was considered to be a novel "structural" antioxidant and characterized as a "radical sponge" by Krusic et $\mathrm{al}^{7}$. Water-soluble fullerene $\mathrm{C}_{60}$ is nontoxic at low physiological concentrations, ${ }^{8,9}$ which is able to penetrate through the membrane of cells ${ }^{10,11}$ and have strong antioxidant properties. ${ }^{8}$ Moreover, it has been found that fullerene $\mathrm{C}_{60}$ possesses anticancer activity. ${ }^{12,13}$

In this study, we aimed to explore if water-soluble $\mathrm{C}_{60}$ $\left(\mathrm{C}_{60}(\mathrm{OH})_{22}\right)$ can exhibit antifibrotic activity in a murine model of bleomycin (BLM) induced pulmonary fibrosis by its antioxidant role.

\section{Materials and Methods}

\section{Animals}

Specific pathogen-free (SPF) C57BL/6J mice were purchased from the Animal Center of Peking University (Beijing, China), and fed under SPF conditions in the basic Medical Research Center of Beijing Chaoyang Hospital affiliated to Capital Medical University. Male mice aged 7-8 weeks and weighing $22-25 \mathrm{~g}$ were used for the preparation of bleomycin-induced pulmonary fibrosis in mice. The care and use of laboratory animals in this study was according to the National Institutes of Health guide strictly. This study was approved by the Animal Care and Utilization Committee of Capital Medical University (AEEI-2014-034).

\section{Preparation of Water-Soluble $\mathrm{C}_{60}$ and Pirfenidone}

$\mathrm{C}_{60}(\mathrm{OH})_{22}$ with purity of more than $99.9 \%$ was obtained from Suzhou Dade Carbon Nanotechnology Co., Ltd. $\mathrm{C}_{60}$ $(\mathrm{OH})_{22}$ was dissolved in sterilized and apyrogenic physiological saline $(0.9 \%)$. Pirfenidone was purchased from Beijing Continent Pharmaceutical Co. Ltd.

\section{Experimental Design}

The animals were randomly divided into 10 groups in the following way.
For exploring the preventive effects are there 1) NS (normal saline) group-mice received saline only; 2) BLM group-mice received BLM, treatment-saline (per day); 3) $1 \mathrm{mg} / \mathrm{kg}$ group-mice received BLM, treatment- $\mathrm{C}_{60}(\mathrm{OH})_{22}$ $1 \mathrm{mg} / \mathrm{kg} / \mathrm{day}$; 4) $10 \mathrm{mg} / \mathrm{kg}$ group-mice received BLM, treatment $-\mathrm{C}_{60}(\mathrm{OH})_{22} \quad 10 \mathrm{mg} / \mathrm{kg} /$ day; 5) $100 \quad \mathrm{mg} / \mathrm{kg}$ group-mice received BLM, treatment- $\mathrm{C}_{60}(\mathrm{OH})_{22}$, $100 \mathrm{mg} / \mathrm{kg} / \mathrm{day}$; 6) $500 \mathrm{mg} / \mathrm{kg}$ group-mice received BLM, treatment $-\mathrm{C}_{60}(\mathrm{OH})_{22}, 500 \mathrm{mg} / \mathrm{kg} /$ day.

For exploring the therapeutic effects are there 1) NS group - mice received saline only; 2) BLM group-mice received BLM, treatment-saline (per day); 3) BLM $+\mathrm{C}_{60}$ group-mice received BLM, treatment- $\mathrm{C}_{60}(\mathrm{OH})_{22} 10 \mathrm{mg} /$ $\mathrm{kg} /$ day; 4) $\mathrm{BLM}+$ pirfenidone group-mice received BLM, treatment-pirfenidone $300 \mathrm{mg} / \mathrm{kg} /$ day.

All mice (except NS group) were treated with a single intratracheal injection of 3.5 (preventive) or 2.0 (therapeutic) $\mathrm{mg} / \mathrm{kg}$ body weight BLM hydrochloride diluted by saline. ${ }^{14} \mathrm{C}_{60}(\mathrm{OH})_{22}$ and pirfenidone were administered intraperitoneal injection beginning from the first day (preventive) and $14^{\text {th }}$ day (therapeutic) until mice were sacrificed after 21 days (preventive) and 28 days (therapeutic) after intratracheal injection of BLM (Figure 1). Moreover, blood, bronchoalveolar lavage fluid (BALF) and lung tissue were collected as previously described, ${ }^{15}$ the left lung was fixed by $10 \%$ formaldehyde solution, the right lung was frozen at $-80^{\circ} \mathrm{C}$ for using.

\section{Lung Histological Assessment}

The collection of mouse lungs for histology was performed as conventional treatment. ${ }^{16}$ Briefly, the lung was fixed (by $10 \%$ formaldehyde solution), dehydrated, paraffin-embedded, and cut into 4- $\mu \mathrm{m}$ sections. Lung sections were stained with $\mathrm{H} \& \mathrm{E}$ and Masson's trichrome stain for assessment of pathological changes. ${ }^{17}$ Immunostaining was performed using antibodies against Collagen I (Abcam, Cambridge, USA), surfactant

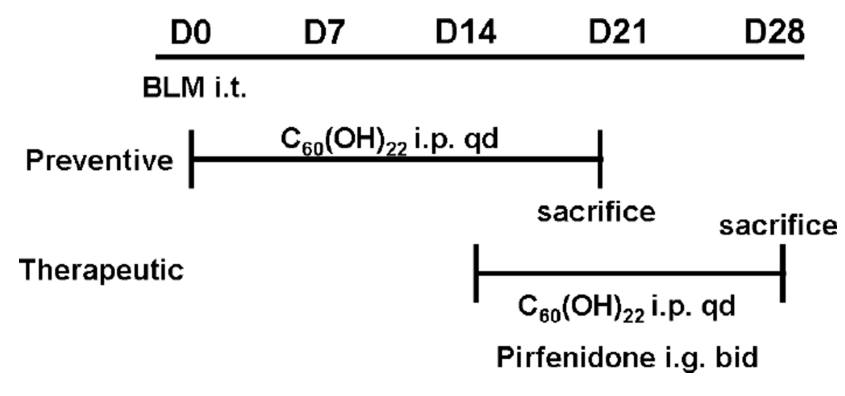

Figure I Treatment and experimental regimen.

Abbreviations: i.t., injection via the intratracheal route; i.p., intraperitoneal injection; i.g., intragastric administration; qd, once a day; bid, twice a day. 
protein C (Abcam, Cambridge, USA) and alpha smooth muscle ( $\alpha$-SMA) antibody (Abcam, Cambridge, USA).

\section{Hydroxyproline Assay}

The content of hydroxyproline in the lung were measured using conventional methods. ${ }^{18}$ The content of hydroxyproline was calculated based upon the lung weight, and the data were expressed as micrograms of hydroxyproline in each gram of lung tissue.

\section{ELISA}

Concentrations of TGF- $\beta_{1}$ and TNF- $\alpha$ in lung tissue, BALF and plasma were determined using ELISA kits (Invitrogen, USA) according to the manufacturer's instructions.

\section{Protein Extraction and Western Blot Analysis}

Frozen lung tissues were homogenized using RIPA buffer (Solarbio, Beijing, China) containing 1:100 phenylmethylsulfonyl fluoride (PMSF) and phosphatase inhibitors. The total protein concentration was resuspended in protein loading buffer containing 5\% mercaptoethanol. The proteins were separated by $8 \%$ sodium dodecyl sulfate polyacrylamide gel electrophoresis (SDS-PAGE) (Bio-Rad, Hercules, CA, USA) using a Mini-Protean electrophoresis module assembly (Bio$\mathrm{Rad})$ at $80 \mathrm{mV}$ and transferred to nitrocellulose membranes (Millipore, Billerica, MA, USA) for 100 min using the Mini Trans-Blot electrophoresis transfer cell (Bio-Rad) at $300 \mathrm{~mA}$. The membranes were treated with anti-rabbit or anti-mouse IgG (LI-COR, Lincoln, NE, USA). Positive bands were visualized, and the intensity of the bands was evaluated using a LI-COR Odyssey. The primary antibodies used were antifibronectin antibody (Abcam, Cambridge, USA), anti- $\alpha$-SMA antibody (Abcam, Cambridge, USA) and anti- $\beta$ actin antibody (Abcam, Cambridge, USA).

\section{Survival Analysis}

We performed survival analysis in each preventive group $(\mathrm{n}=9-10)$. Survival time of each mouse was recorded until $21^{\text {st }}$ day after BLM or saline administration.

\section{Measurement of ROS Concentration}

The content of ROS was measured by using DCFH-DA as the manufacturer's instructions, which was purchased from Nanjing Jiancheng Bioengineering Institute.

\section{Statistical Analysis}

All data were expressed as the mean \pm SD. All experiments were conducted with three independent replications. GraphPad Prism 6 (GraphPad, La Jolla, CA, USA) was used for statistical analyses using $t$-test or one-way analysis of variance; $P<0.05$ was considered to indicate statistically significant differences in all comparisons.

\section{Results}

The Optimal Dose of $\mathrm{C}_{60}(\mathrm{OH})_{22}$ for Pulmonary Fibrosis Was $10 \mathrm{mg} / \mathrm{kg} /$ day Survival Time

The mortality had a significant difference between preventive groups. All mice in NS group survived for 21 days. However, substantial mortality of mice was demonstrated in BLM group, and a significant change of median survival time existed between the group treated with $\mathrm{C}_{60}(\mathrm{OH})_{22}$ $10 \mathrm{mg} / \mathrm{kg} / \mathrm{day}$ and the BLM group (Figure 2A). Up to the $21^{\text {st }}$ day, $30 \%$ of mice survived in BLM group, $44.4 \%$ in $\mathrm{C}_{60}$ $(\mathrm{OH})_{22} 1 \mathrm{mg} / \mathrm{kg}$ group and $100 \mathrm{mg} / \mathrm{kg}$ group, $66.7 \%$ in $10 \mathrm{mg} / \mathrm{kg}$ group, and no mice survived in $500 \mathrm{mg} / \mathrm{kg}$ group. These results indicated that $\mathrm{C}_{60}(\mathrm{OH})_{22}$ could protect mice from death when mice were treated with the dose of $10 \mathrm{mg} / \mathrm{kg} /$ day and $1 \mathrm{mg} / \mathrm{kg} / \mathrm{day}$, but the mice treated with $\mathrm{C}_{60}(\mathrm{OH})_{22}$ by the dose of $100 \mathrm{mg} / \mathrm{kg} /$ day had no difference with BLM group, what is more, $\mathrm{C}_{60}(\mathrm{OH})_{22}$ with a dose of $500 \mathrm{mg} / \mathrm{kg} /$ day had injury but no advantage.

\section{Body Weight}

Body weight of mice in preventive groups (except NS group) had a significant decrease. However, compared to BLM group, the mice in $10 \mathrm{mg} / \mathrm{kg}$ group had a slight decrease, but the difference was not significant (Figure 2B).

\section{$\mathrm{C}_{60}(\mathrm{OH})_{22}$ Had a Therapeutic Effect in the Advanced Stages of BLM-Induced Pulmonary Fibrosis Computed Tomography Images of Mice Lung}

CT images of mice lung on the 28th day after BLM or saline administration are shown in Figure 2A. Lungs in the BLM groups demonstrated some consolidated shadows compared with the NS group (Figure 3A). However, compared with BLM group, the images of lungs in $\mathrm{BLM}+\mathrm{C}_{60}$ group revealed decreased density and diffuse ground-glass opacities with or without areas of consolidation (Figure 3A), but quantitative evaluation was difficult. 

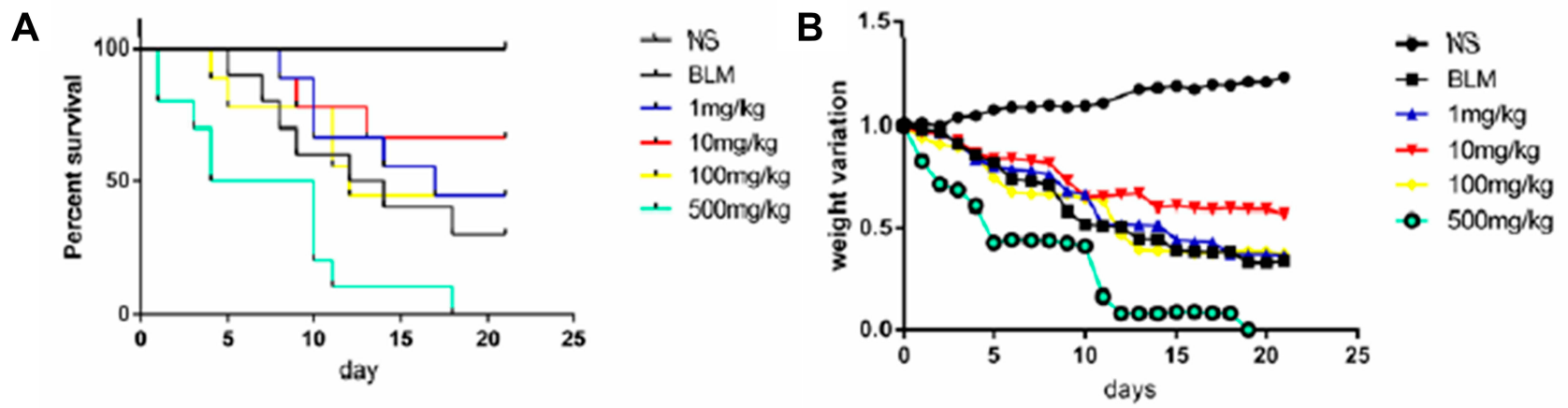

Figure 2 Effect of $\mathrm{C}_{60}(\mathrm{OH})_{22}$ on survival time and body weight. The doses of $\mathrm{I}, 10,100$ and $500 \mathrm{mg} / \mathrm{kg}$ of $\mathrm{C}_{60}(\mathrm{OH})_{22}$ were administered intraperitoneal injection to the mice for 21 days after intratracheal injection of BLM. Kaplan-Meier survival curves (A) and body weight change (B) were noted.

Abbreviations: NS, no treatment; BLM, bleomycin.

\section{H\&E and MASSON}

BLM-induced pulmonary injury and fibrosis in mice were monitored by histopathological analysis. It was shown that BLM instillation produced a significant increase of fibrosis in the lung by H\&E-stained sections. BLM-induced fibrotic mice demonstrated increased pulmonary parenchymal distortion, showing thicker alveolar membrane, collapsed alveoli, and inflammatory cell infiltration (Figure 3A). Masson's trichrome staining of collagen was used to demonstrate that BLM induced severe collagen deposition in mice. However, $\mathrm{C}_{60}$ $(\mathrm{OH})_{22}$ and pirfenidone administration markedly ameliorated lung injuries and evidently attenuated collagen deposition (Figure 3A).

\section{Hydroxyproline}

Hydroxyproline was concentrated in BLM-induced inflammatory response, and there was a positive correlation between the level of hydroxyproline and collagen. As illustrated (Figure 3C), the hydroxyproline was significantly increased after BLM administration while reversed after $\mathrm{C}_{60}(\mathrm{OH})_{22}$ and pirfenidone treatment.

\section{Collagen I, $\alpha$-SMA and Fibronectin}

We subsequently investigated the ability of $\mathrm{C}_{60}(\mathrm{OH})_{22}$ to modulate the expression of collagen I, $\alpha$-SMA and fibronectin which were key markers of pulmonary fibrosis. The results showed that the lung tissues from BLM treated mice were markedly up-regulated the expression of collagen I, $\alpha$-SMA and fibronectin (Figure 3A and B). Impressively, levels of $\alpha-$ SMA and fibronectin were obviously reduced after $\mathrm{C}_{60}(\mathrm{OH})_{22}$ and pirfenidone treatment (Figure 3B). The expression of collagen I was monitored by immunohistochemical analysis. Lung sections of mice in NS group showed weak positive staining of collagen I, while intratracheal instillation of BLM resulted in markedly increased expression of collagen I in lung tissues. The administration $\mathrm{C}_{60}$ or pirfenidone largely decreased the expression of collagen I compared with BLM group (Figure $3 \mathrm{~A}$ and $\mathrm{D}$ ). These results directly reflected the attenuation effect of $\mathrm{C}_{60}(\mathrm{OH})_{22}$ on BLM-induced pulmonary fibrosis in mice.

\section{Mechanisms for the Therapeutic Effect of $\mathrm{C}_{60}(\mathrm{OH})_{22}$ on BLM-Induced Pulmonary Fibrosis ROS}

The levels of ROS were determined in the lung tissue in order to investigate the effect of $\mathrm{C}_{60}(\mathrm{OH})_{22}$ against the oxidative stress in BLM-induced lung fibrosis (Figure 4A). A significant rise in the level of ROS in lung tissue was observed in the BLM treated animals, while it was reversed after $\mathrm{C}_{60}(\mathrm{OH})_{22}$ administration $(P<0.05)$.

TGF- $\beta_{\text {I }}$ and TNF- $\alpha$

TGF- $\beta_{1}$ and TNF- $\alpha$ play important roles in the pathogenesis and exacerbation of pulmonary fibrosis, ${ }^{19}$ and we assessed the effect of $\mathrm{C}_{60}(\mathrm{OH})_{22}$ on their expression. As shown in Figure 4E and F., the expression of TGF- $\beta_{1}$ and TNF- $\alpha$ in lung tissue, BALF and plasma were significantly increased in BLM group compared with NS group while it was decreased after $\mathrm{C}_{60}$ $(\mathrm{OH})_{22}$ administration, which suggested that $\mathrm{C}_{60}(\mathrm{OH})_{22}$ could inhibit the expression of TGF- $\beta_{1}$ and TNF- $\alpha$.

\section{AEC II and $\alpha$-SMA}

Type 2 alveolar epithelial cells (AEC II) were marked with surfactant protein $\mathrm{C}$ (SPC) by immunohistochemistry (Figure 4B and C). Compared with NS group, lung sections 
A
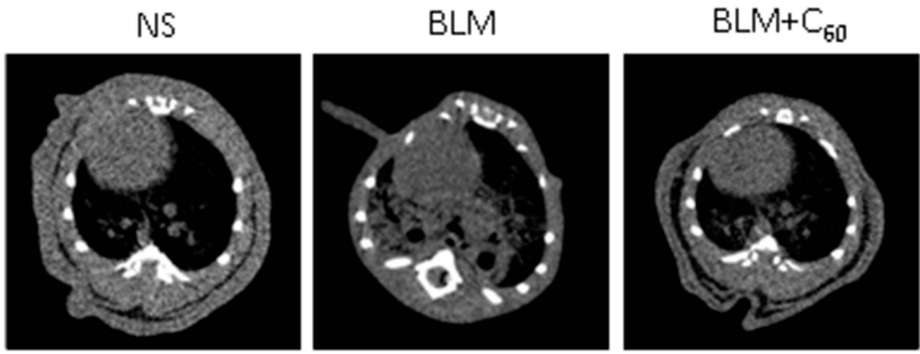

BLM+pirfenidone
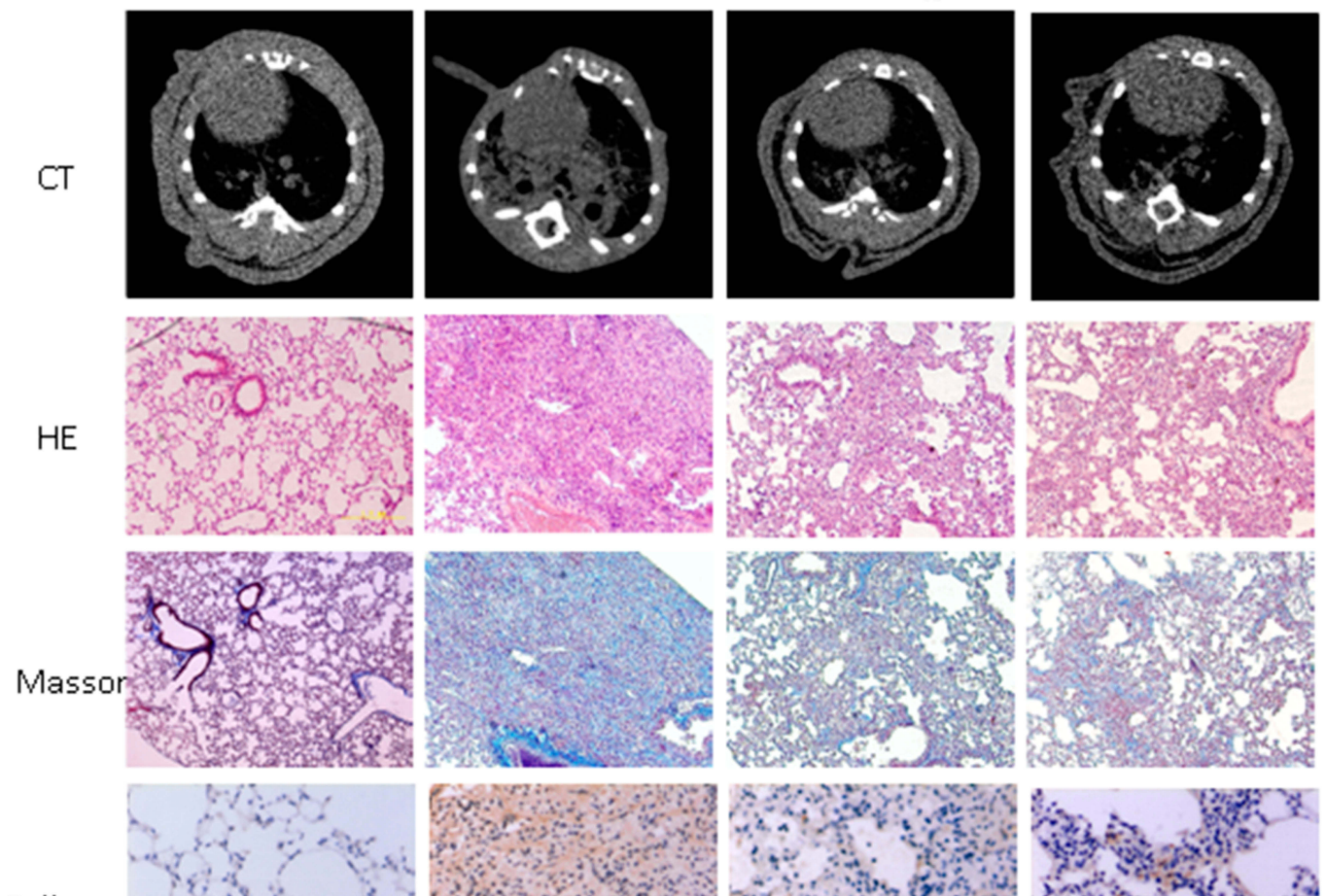

Collager
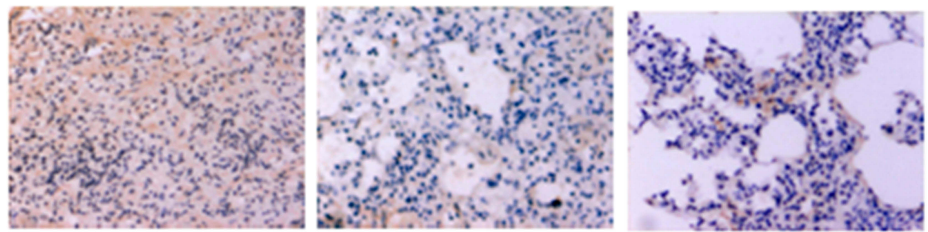

B

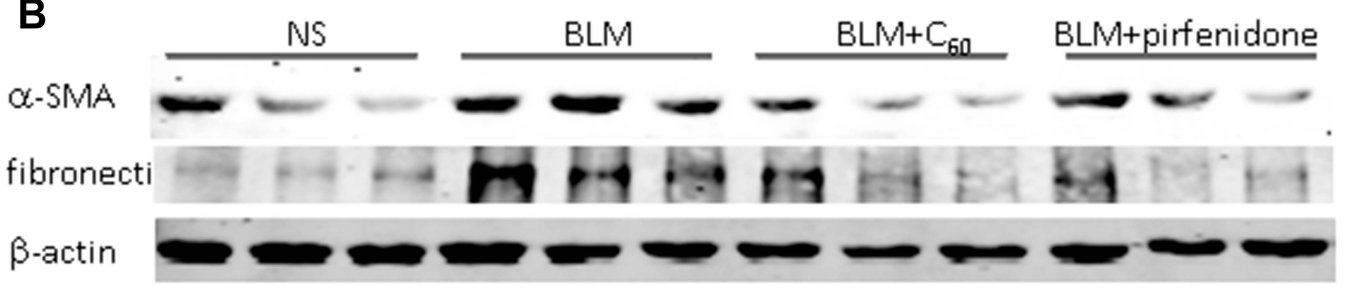

C
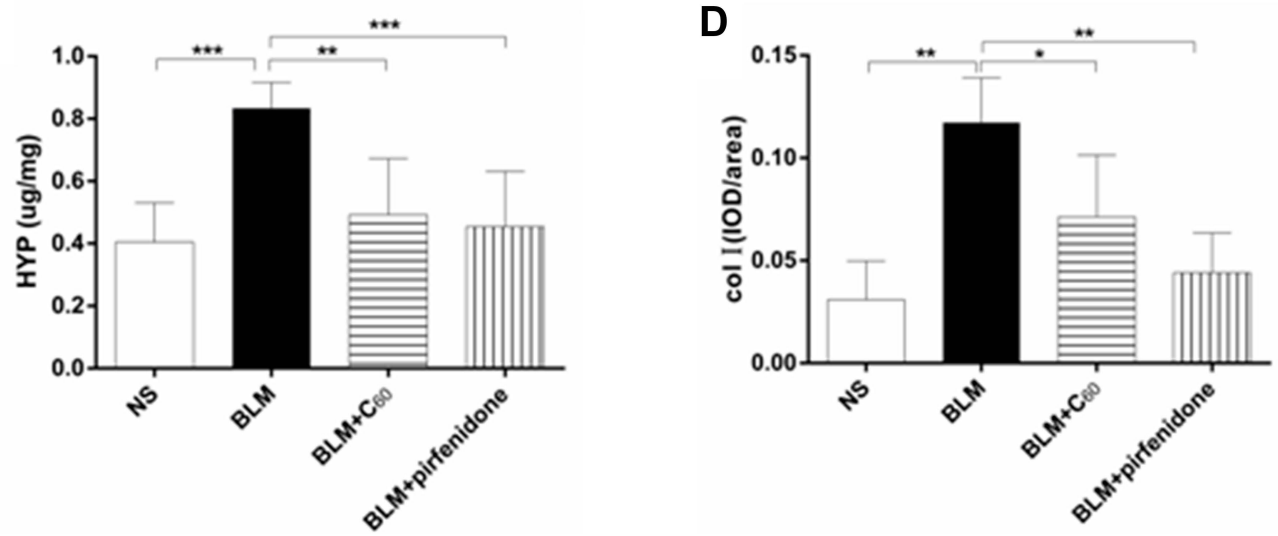

Figure 3 Examination of the antifibrotic effects of $\mathrm{C}_{60}(\mathrm{OH})_{22}$ and pirfenidone on BLM-induced pulmonary fibrosis in mice. Chest CT and H\&E and Masson-stained sections were observed after BLM or saline administration in the NS, BLM, BLM+C 60 and BLM+pirfenidone groups (A). Collagen deposition was monitored by immunohistochemical analysis $(\mathbf{A})$, and date was reported as means \pm SD (D). Fibronectin and $\alpha$-SMA were quantified by Western blot (B). The content of hydroxyproline was determined in lung tissues, which is a marker of collagen deposition (C). $* P<0.05 ; * * P<0.01 ; * * * P<0.001$.

Abbreviations: NS, no treatment; BLM, bleomycin; HYP, hydroxyproline; col I, collagen I. 

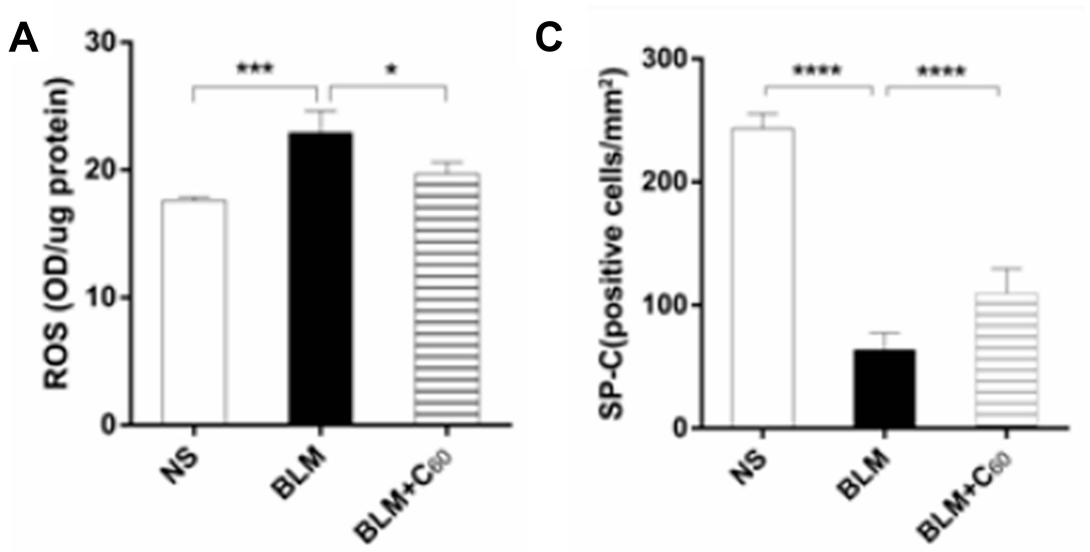

B
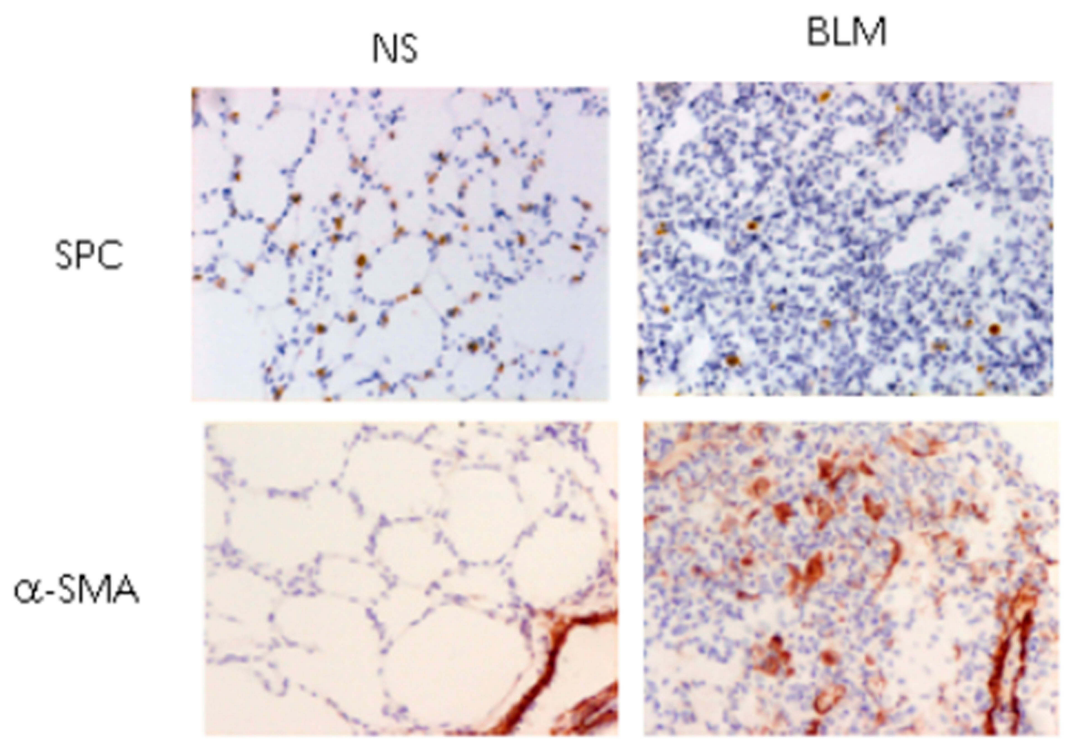
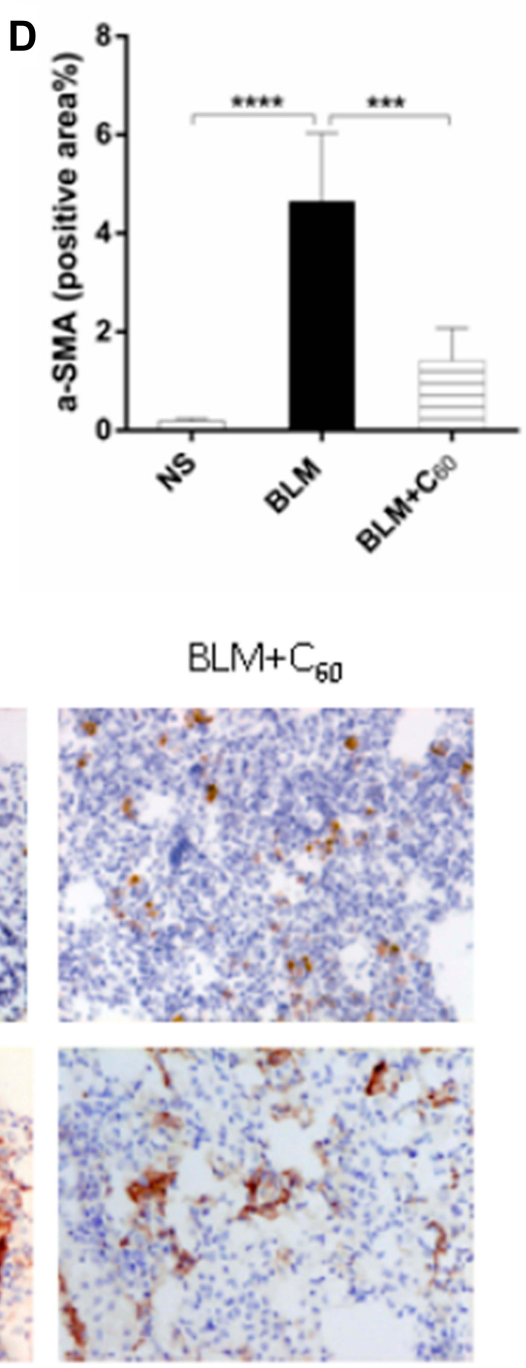

E

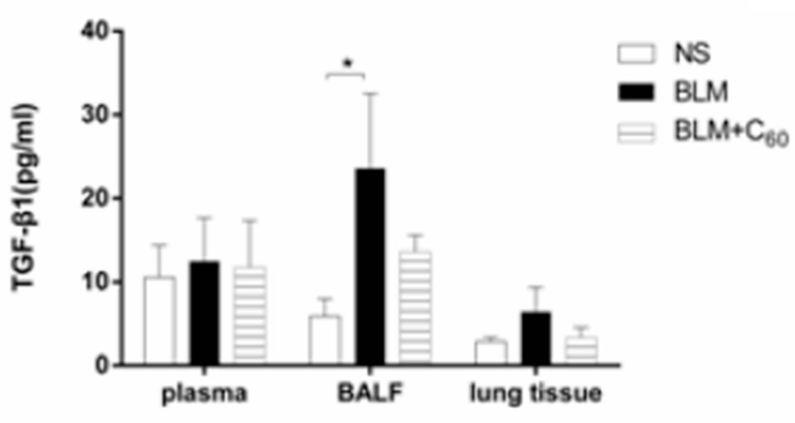

$\mathbf{F}$

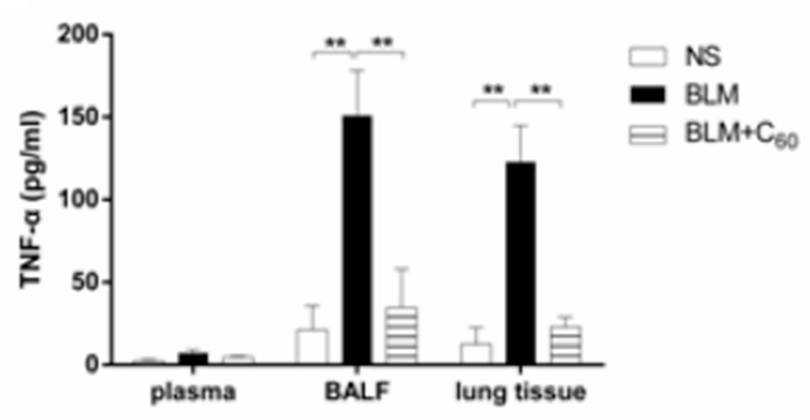

Figure 4 Mechanisms for the therapeutic effect of $\mathrm{C}_{60}(\mathrm{OH})_{22}$ on BLM-induced pulmonary fibrosis. The content of ROS was tested in lung tissues $(\mathbf{A})$. AEC II was marked with SPC by immunohistochemistry $(\mathbf{B})$, and date was reported as mean $\pm \mathrm{SD}(\mathbf{C})$. $\alpha$-SMA was monitored by immunohistochemical (B), as the marker of fibroblast, and was reported as mean \pm SD (D). The expression of TGF- $\beta_{I}$ and TNF- $\alpha$ in lung tissue, BALF and plasma were determined and reported as means \pm SD $(\mathbf{E}$ and F). $* P<0.05 ; * * P<0.01 ; * * * P<0.001 ; * * * * P<0.0001$. Abbreviations: NS, no treatment; BLM, bleomycin; SPC, surfactant protein C; AEC II, type 2 alveolar epithelial cells; ROS, reactive oxygen species.

of BLM group were characterized by a significant decrease in the number of AECII, while, the number rose again in mice receiving $\mathrm{C}_{60}$ group. $\alpha$-SMA was monitored by immunohistochemical to reflect the amount of fibroblast. The sections in the NS group showed weak positive staining of $\alpha$ SMA, while increasing expression was showed in BLM group 
(Figure 4B and D). These results directly reflected that $\mathrm{C}_{60}$ $(\mathrm{OH})_{22}$ could decrease the apoptosis of AEC II and the amount of fibroblast by easing oxidative stress.

\section{Discussion}

In this study, water-soluble $\mathrm{C}_{60}$ was found to serve as an antifibrotic agent for BLM-induced mouse pulmonary fibrosis, which has been used as a classic model for the evaluation of the antifibrotic effect. ${ }^{20}$ The results showed that BLM could induce pulmonary fibrosis and cause mice death, body weight loss and exacerbated lung histopathology abnormalities with collagen deposition. However, these adverse consequences caused by BLM were effectively attenuated by water-soluble $\mathrm{C}_{60}$. Our study had shown that water-soluble $\mathrm{C}_{60}$ possessed significant anti-inflammation and anti-oxidant effects on BLM-induced lung damage in mice. To the best of my knowledge, it is the first time to detect the role of $\mathrm{C}_{60}$, a novel "structural" antioxidant, in pulmonary fibrosis mice induced by bleomycin.

It has been reported by many studies that oxidative stress is closely related to the development of IPF. ${ }^{5,6,21}$ The excessive production of ROS plays a key role in oxidative stress, and ROS is also an important medium in the process of pulmonary fibrosis. It has been shown that ROS can make single-stranded DNA damage and fracture, resulting in AEC injury and necrosis. And the excessive production of ROS can induce AEC apoptosis by activating the death receptor pathway, ${ }^{22}$ mitochondrial death pathway ${ }^{23}$ and endoplasmic reticulumassociated death. ${ }^{24}$ Therefore, the activation of fibroblast and the deposition of collagen are promoted, and then, pulmonary fibrosis progresses. Our study showed that water-soluble $\mathrm{C}_{60}$ can significantly reduce the concentration of ROS in lung tissue. And we observed that water-soluble $\mathrm{C}_{60}$ could reduce the apoptosis and/or necrosis of AEC and decreased fibroblast activation. These results suggest that the development of IPF would be inhibited by water-soluble $\mathrm{C}_{60}$.

In addition, ROS could regulate signal transduction. ${ }^{25}$ ROS could increase the expression of TGF- $\beta_{1}$, TNF- $\alpha$, interleukin, platelet-derived growth factor Chaudhary et al. ${ }^{26}$ Among them, TGF- $\beta_{1}$ plays a key role in pulmonary fibrosis which is called the "master switch" of organ fibrosis (including pulmonary fibrosis). ${ }^{27}$ To a certain extent, the degree of inflammation and fibrosis is depended on the quantity of TGF- $\beta_{1} \cdot{ }^{28,29}$ Apoptosis of AEC was mediated by TNF- $\alpha$. TNF- $\alpha$ which is an important factor in the process of pulmonary fibrosis was up-regulated the expression of TGF- $\beta_{1}{ }^{30}$ The over-expression of these cytokines aggravated the damage and apoptosis of cells and advanced the development of pulmonary fibrosis. While ROS has been shown to activate these cytokines, and these cytokines also increase the production of ROS in human lung fibroblasts, so a vicious circle formed. In our study, we observed that the content of TGF- $\beta_{1}$ and TNF- $\alpha$ significantly decreased in the lungs of mice after treated with $\mathrm{C}_{60}(\mathrm{OH})_{22}$ compared with BLM group, suggesting water-soluble $\mathrm{C}_{60}$ could reduce the expression of TGF- $\beta_{1}$ and TNF- $\alpha$. Therefore, eventually, alleviate inflammation and inhibit fibrosis by reducing the content of ROS.

IPF is a chronic and fatal disease, and the management of IPF is highly debatable and no curative treatment has been developed except for pirfenidone and nintedanib. However, adverse events such as gastrointestinal symptoms, photosensitivity and fatigue might occur at pirfenidone administration. ${ }^{31,32}$ And nintedanib slowed disease progression with side-effect profiles such as hepatic enzymes increased, Mazzei et $\mathrm{al}^{33}$ However, Gharbi et al have shown that fullerene $\mathrm{C}_{60}$ is a powerful antioxidant with no acute or subacute toxicity. ${ }^{8,9}$ Baati et al have found that the lifespan of rats would be prolonged by repeated oral administration of fullerene $\mathrm{C}_{60}{ }^{34}$ Therefore fullerene $\mathrm{C}_{60}$ is likely to be a new management of IPF.

\section{Conclusion}

It was demonstrated that water-soluble $\mathrm{C}_{60}$, a novel "structural" antioxidant, could reduce the severity of pulmonary fibrosis induced by BLM in mice. Therefore, water-soluble $\mathrm{C}_{60}$ probably has a great potential for IPF therapeutic applications.

\section{Acknowledgments}

This work was supported by grants from National Natural Science Foundation of China [Nos. 81430001, 81470258 and 81871328] and Beijing Natural Science Foundation [No. 7182149].

\section{Disclosure}

The authors declare no conflicts of interest in this work.

\section{References}

1. Raghu G, Collard HR, Egan JJ, et al. An official ATS/ERS/JRS/ALAT statement: idiopathic pulmonary fibrosis: evidence-based guidelines for diagnosis and management. Am $J$ Respir Crit Care Med. 2011;183(6):788-824. doi:10.1164/rccm.2009-040GL

2. Selman M, King TE, Pardo A. Idiopathic pulmonary fibrosis: prevailing and evolving hypotheses about its pathogenesis and implications for therapy. Ann Intern Med. 2001;134(2):136-151. doi:10.7326/00034819-134-2-200101160-00015

3. Wadsworth RM. Oxidative stress and the endothelium. Exp Physiol. 2008;93(1):155-157. doi:10.1113/expphysiol.2007.038687 
4. Teixeira KC, Soares FS, Rocha LG, et al. Attenuation of bleomycin-induced lung injury and oxidative stress by N-acetylcysteine plus deferoxamine. Pulm Pharmacol Ther. 2008;21(2):309-316. doi:10.1016/j.pupt.2007.07.006

5. Cantin AM, North SL, Fells GA, et al. Oxidant-mediated epithelial cell injury in idiopathic pulmonary fibrosis. J Clin Invest. 1987;79 (6):1665-1673. doi:10.1172/JCI113005

6. Daniil ZD, Papageorgiou E, Koutsokera A, et al. Serum levels of oxidative stress as a marker of disease severity in idiopathic pulmonary fibrosis. Pulm Pharmacol Ther. 2008;21(1):26-31. doi:10.1016/j. pupt.2006.10.005

7. Krusic PJ, Wasserman E, Keizer PN, et al. Radical reactions of c60. Science. 1991;254(5035):1183-1185. doi:10.1126/science.254.5035.1183

8. Gharbi N, Pressac M, Hadchouel M, et al. [60]fullerene is a powerful antioxidant in vivo with no acute or subacute toxicity. Nano Lett. 2005;5(12):2578-2585. doi:10.1021/n1051866b

9. Johnston HJ, Hutchison GR, Christensen FM, et al. The biological mechanisms and physicochemical characteristics responsible for driving fullerene toxicity. Toxicol Sci. 2010;114(2):162-182. doi:10.1093/ toxsci/kfp265

10. Qiao R, Roberts AP, Mount AS, et al. Translocation of C60 and its derivatives across a lipid bilayer. Nano Lett. 2007;7(3):614-619. doi:10.1021/nl062515f

11. Prylutska S, Bilyy R, Overchuk M, et al. Water-soluble pristine fullerenes $\mathrm{C} 60$ increase the specific conductivity and capacity of lipid model membrane and form the channels in cellular plasma membrane. J Biomed Nanotechnol. 2012;8(3):522-527. doi:10.1166/jbn.2012.1404

12. Shi J, Wang L, Gao J, et al. A fullerene-based multi-functional nanoplatform for cancer theranostic applications. Biomaterials. 2014;35(22):5771-5784. doi:10.1016/j.biomaterials.2014.03.071

13. Panchuk RR, Prylutska SV, Chumakl VV, et al. Application of C60 Fullerene-doxorubicin complex for tumor cell treatment in vitro and in vivo. J Biomed Nanotechnol. 2015;11(7):1139-1152. doi:10.1166/ jbn.2015.2058

14. Li XX, Jiang DY, Huang XX, et al. Toll-like receptor 4 promotes fibrosis in bleomycin-induced lung injury in mice. Genet Mol Res. 2015;14(4):17391-17398. doi:10.4238/2015.December.21.8

15. Jiang D, Liang J, Hodge J, et al. Regulation of pulmonary fibrosis by chemokine receptor CXCR3. J Clin Invest. 2004;114(2):291-299. doi:10.1172/JCI16861

16. Jiang DY, Huang XX, Jing G, et al. Pulmonary fibrosis in a mouse model of sarcoid granulomatosis induced by booster challenge with Propionibacterium acnes. Oncotarget. 2016;7(23):33703-33714. doi:10.18632/oncotarget.9397

17. Hübner RH, Gitter W, El MNE, et al. Standardized quantification of pulmonary fibrosis in histological samples. Biotechniques. 2008;44 (4):507-11, 514-7. doi:10.2144/000112729

18. Sisson TH, Mendez M, Choi K, et al. Targeted injury of type II alveolar epithelial cells induces pulmonary fibrosis. Am J Respir Crit Care Med. 2010;181(3):254-263. doi:10.1164/rccm.200810-1615OC

19. Willis BC, Borok Z. TGF- $\beta$-induced EMT: mechanisms and implications for fibrotic lung disease. Am J Physiol Lung Cell Mol Physiol. 2007;293(3):L525-34. doi:10.1152/ajplung.00163.2007
20. Mouratis MA, Aidinis V. Modeling pulmonary fibrosis with bleomycin. Curr Opin Pulm Med. 2011;17(5):355-361. doi:10.109 7/MCP.0b013e328349ac2b

21. Gao F, Koenitzer JR, Tobolewski JM, et al. Extracellular superoxide dismutase inhibits inflammation by preventing oxidative fragmentation of hyaluronan. $J$ Biol Chem. 2008;283(10):6058-6066. doi:10.1074/jbc.M709273200

22. Liu G, Beri R, Mueller A, Kamp DW. Molecular mechanisms of asbestos-induced lung epithelial cell apoptosis. Chem Biol Interact. 2010;188(2):309-318. doi:10.1016/j.cbi.2010.03.047

23. Fu YQ, Fang F, Lu ZY, et al. N-acetylcysteine protects alveolar epithelial cells from hydrogen peroxide-induced apoptosis through scavenging reactive oxygen species and suppressing c-Jun N-terminal kinase. Exp Lung Res. 2010;36(6):352-361. doi:10.3109/01902 141003678582

24. Jorgensen E, Stinson A, Shan L, et al. Cigarette smoke induces endoplasmic reticulum stress and the unfolded protein response in normal and malignant human lung cells. BMC Cancer. 2008;8 (1):229. doi:10.1186/1471-2407-8-229

25. Rees MD, Kennett EC, Whitelock JM, et al. Oxidative damage to extracellular matrix and its role in human pathologies. Free Radic Biol Med. 2008;44(12):1973-2001. doi:10.1016/j.freeradbiomed. 2008.03.016

26. Chaudhary NI, Roth GJ, Hilberg F, et al. Inhibition of PDGF, VEGF and FGF signalling attenuates fibrosis. Eur Respir J. 2007;29 (5):976-985. doi:10.1183/09031936.00152106

27. Sime PJ, O'Reilly KM. Fibrosis of the lung and other tissues: new concepts in pathogenesis and treatment. Clin Immunol. 2001;99 (3):308-319. doi:10.1006/clim.2001.5008

28. Cuzzocrea S, Genovese T, Failla M, et al. Protective effect of orally administered carnosine on bleomycin-induced lung injury. Am $J$ Physiol Lung Cell Mol Physiol. 2007;292(5):L1095-104. doi:10.1152/ajplung.00283.2006

29. Kang HR, Lee CG, Homer RJ, et al. Semaphorin 7A plays a critical role in TGF- $\beta 1$-induced pulmonary fibrosis. J Exp Med. 2007;204 (5):1083-1093. doi:10.1084/jem.20061273

30. Failla M, Genovese T, Mazzon E, et al. Pharmacological inhibition of leukotrienes in an animal model of bleomycin-induced acute lung injury. Respir Res. 2006;7(1):137. doi:10.1186/1465-9921-7-137

31. Takeda Y, Tsujino K, Kijima T, et al. Efficacy and safety of pirfenidone for idiopathic pulmonary fibrosis. Patient Prefer Adherence. 2014;8:361-370. doi:10.2147/PPA

32. Valeyre D, Albera C, Bradford WZ, et al. Comprehensive assessment of the long-term safety of pirfenidone in patients with idiopathic pulmonary fibrosis. Respirology. 2014;19(5):740-747. doi:10.1111/ resp. 12297

33. Mazzei ME, Richeldi L, Collard HR. Nintedanib in the treatment of idiopathic pulmonary fibrosis. Ther Adv Respir Dis. 2015;9 (3):121-129. doi:10.1177/1753465815579365

34. Baati T, Bourasset F, Gharbi N, et al. The prolongation of the lifespan of rats by repeated oral administration of [60]fullerene. Biomaterials. 2012;33(19):4936-4946. doi:10.1016/j.biomaterials.2012.03.036
International Journal of Nanomedicine

\section{Publish your work in this journal}

The International Journal of Nanomedicine is an international, peerreviewed journal focusing on the application of nanotechnology in diagnostics, therapeutics, and drug delivery systems throughout the biomedical field. This journal is indexed on PubMed Central, MedLine, CAS, SciSearch ${ }^{\mathbb{B}}$, Current Contents ${ }^{\mathbb{B}} /$ Clinical Medicine, $^{2}$
Journal Citation Reports/Science Edition, EMBase, Scopus and the Elsevier Bibliographic databases. The manuscript management system is completely online and includes a very quick and fair peer-review system, which is all easy to use. Visit http://www.dovepress.com/ testimonials.php to read real quotes from published authors. 